\title{
Level of Aspiration on Academic Performance of School Students
}

\author{
Binda Kumari ${ }^{1}$
}

Keywords: Aspiration, Academic Performance, School Students

\begin{abstract}
Abraham Maslow's hierarchy, he described this high-level need in the following way:"What a man can be, he mustbe. This need we may call self-actualization...It refers to the desire for selffulfillment, namely, to the tendency for him to become actualized in what he is potentially. This tendency might be phrased as the desire to become more and more what one is, to become everything that one is capable of becoming."
\end{abstract}

In recent times, student aspiration for higher education has become the subject of Government policy and school / University partnerships. Gardner (1940) defined as, "level of aspiration is a truly quantitative concept, which has two requirements that the subjects make some public indication of his aims and that, he makes this in quantitative terms.” Hurlock (1967) defined it as “a longing for what is above one's achieved level with advancement on it as it send. In other words, aspiration means the goal an individual sets for himself in a task, which has intense personal significance for him or in which he is ego-involved.” The research was undertaken in three stages: survey instrument development and refinement; implementation; and data analysis.

\section{REVIEW OF LITERATURE}

Parent involvement in a child's early education is consistently found to be positively associated with a child's academic performance (Hara \& Burke, 1998; Hill \& Craft, 2003; Marcon, 1999; Stevenson \& Baker, 1987). Specifically, children whose parents are more involved in their education have higher levels of academic performance than children whose parents are involved to a lesser degree.

Goel (2004) instigated the effect of home environment on educational aspirations. The sample of the study comprised 100 students (50 boys and 50 girls) of intermediate classes in age groups of 16-20 years. The results revealed that girls had much higher educational aspiration than boys. Boys felt more rejected with the autocratic atmosphere at home in comparison to girls who experienced more nurturance than boys.

\footnotetext{
${ }^{1}$ HOD \& Assistant Professor, Department of Psychology, Kartik Oraon College, Ratu, Ranchi University, Ranchi, Jharkhand (C) 2015 I B Kumari; licensee IJIP. This is an Open Access Research distributed under the terms of the Creative Commons Attribution License (http://creativecommons.org/licenses/by/2.0), which permits unrestricted use, distribution, and reproduction in any Medium, provided the original work is properly cited.
} 


\section{Level of Aspiration on Academic Performance of School Students}

Gupta (1987) studied relationship between locus of control, anxiety, personality traits, level of aspiration and academic achievement of secondary school students with the objective to assess the magnitude and direction of relationship of locus of control, anxiety, personality traits, level of aspiration with academic achievement by taking a sample of 670 students of average intelligence drawn from a population of 3780 students of class XI of Hindi medium school of Allahabad city and found that locus of control, anxiety, level of aspiration was correlated negatively with academic achievement; socio economic status had significant positive correlation with academic achievement; boys were high achievers, more internally controlled and less anxious than girls.

Narula (2007) in her study on a sample of 700 students of ninth class studying in senior secondary schools of Punjab concluded significant positive correlation between the variables of creativity and academic achievement. Significant difference was also obtained between the creativity of boys and girls at 0.01 level of significance.

\section{METHODOLOGY}

\section{Objective}

The main objectives of study were as under:

1. To measure the self - actualization in school student relation to their social economic status.

2. To measure the academic performance in school student on level of aspiration.

3. To measure the correlation between male and female on Academic Performance.

\section{Hypothesis}

1. There is no significant between academic performances in school students relation to their socio-economic status.

2. There is no significant difference in the academic performance between boys and girls on level of aspiration .

3. There is a significant difference in the overall quality of life between school students (boys and girls) with academic performance.

\section{Sample}

The sample will consist of 300 school students selected by stratified random sampling. The factors of stratification will be:

- Religion - 2 (Tribal and non Tribal)

- Gender - 2 (Male and Female)

- Level of Education - 3 (Class $10^{\text {th }}, \& 12^{\text {th }}$ )

\section{Tools}

For this purpose the following test tools were considered with their reliability, Validity and objectivity mention in their respective manuals. In present study two inventory used in research. 
- Personal Data Questionnaire : This questionnaire will be prepared by the research scholar. It will be used to obtain information about respondents' name, age gender, religion, caste, education and socio-economic status of the parents etc.

- Self-actualization inventory : Self-actualization inventory made by Sharma K. N. (1987). It consists 75 items. This is 3 point scale. The test retest reliability of whole test was 0.85 and validity of this scale is very high.

\section{PROCEDURE}

This study was designed to compare Tribal and Non-tribal school students on level of aspiration and academic performance. As such, descriptive method of research was employed.

\section{Statistical treatment:}

The data collected was subjected to the following statistical treatment Mean S.D t-test

\section{Analysis and interpretation of data:}

In order to achieve the objectives formulated for the study, the data was statically analyzed by employing t-test.

\section{RESULT}

\section{Table.1}

Showing mean comparison of Tribal and Non- tribal school students on real self dimension of self-actualization ( $\mathrm{N}=150$ in each group). Group N Mean S.D t-value Level of significance Tribal 150255.69 28.45, 21.75 Significant at 0.01 Non-Tribal 150 168.47, 20.70. The perusal of above table shows that the two groups differ significantly on real dimension of self actualization inventory. The calculated t-value (21.75) exceeds the tabulated t-value (2.59) at 0.01 level of significance, which depicts that there is a significant difference between Tribal and non-tribal school students on real admission of self- actualization inventory. Thus from the confirmation of the results from the above table, the hypothesis which reads as, "Tribal and Nontribal school students differ significantly on real self dimension of self-actualization inventory”, stands accepted.

\section{Table. 2}

Showing mean comparison of Tribal and Non-tribal school students on ideal self dimension of self actualization inventory ( $\mathrm{N}=150$ in each group). Group $\mathrm{N}$ Mean S.D t-value Level of significance Tribal 150, 161.14, 14.12, 14.07 Significant at 0.01 level Non - tribal 150, 198.17, 18.16 The perusal of above table shows that the two groups differ significantly on ideal self dimension of self actualization inventory”, stands accepted.

\section{DISCUSSION}

Our purpose in undertaking this study was to determine if the problem of low aspirations among youth was unique to Maine. The results of our analysis have convinced us that low aspirations among Tribal and Non-tribal school students are a problem which exists nationally. It does appear that intervention is possible. Conscious planning and concerted efforts by parents, school 


\section{Level of Aspiration on Academic Performance of School Students}

personnel, concerned citizens and municipal officials, can be effective. The goals, dreams, and ambitions of our school students should not be a function of whether they live in a rural, urban or suburban environment. But the evidence is clear-those who live in rural area are evidencing generally lower aspirations. Rural states have a special responsibility to their students which must be recognized and fulfilled. Certainly, Tribal and Non-tribal school students are deserving of any efforts which can be made to promote higher aspirations.

\section{CONCLUSION}

The results of this study further emphasize upon the significant role played by home in shaping students' Level of Aspiration, no matter what the income level or background of the family is. Hence, parents need to be made aware of the various positive and negative reward mechanisms that can be helpful in enhancing Level of Aspirations of their wards. It becomes foremost duty of parents to make every effort to create a conducive and healthy atmosphere in the home so as to sustain high Educational Aspirations in children. It is very much desired in school students and especially in Tribal and Non-tribal students to have high Level of Aspirations and ambitions for social and scholastic achievement.

\section{SUGGESTIONS}

The further study may be replicated on large sample. A comparative study may be conducted on Level of Asperation on academic performance of Tribal and Non-tribal school students. This study may be undertaken to highlight the different dimensions of Level of Asperation on academic performance of Tribal and Non-tribal school students. Further investigations may be undertaken in relation to carrier aspiration and academic performance in school students.

\section{REFERENCES}

Gardner, W. (1940). The relation of certain personality variables of level of aspiration. The Journal of psychology : Interdisciplinary and applied, Vol 9 (1), p - 191-206, DOI : 10,1080/00223980, 1940,9917686.

Goel, S.P. (2004). Effect of gender, home and environment on educational aspirations. Journal of Community Guidance and Research, 21(1), 77- 81.

Gupta, M. (1987). A Study of Relationship between locus of control, Anxiety, Level of Aspiration, Academic Achievement of Secondary Students., D. Phil. Edu.,Allahabad University. In M.B.Buch, ed. (1991).Fourth Survey of Research in Education ( 1983-1988). New Delhi: National Council for Educational Research and Training, Sri Aurobindo, Marg, PP. 824- 825.

Hara SR, Burke DJ. Parent involvement: The key to improved student achievement. The School Community Journal. 1998;8:9-19.

Maslow, A. (1970). Motivation and personality (2nd ed.). New York: Harper \& Row.

Maslow, A. H. (1943). A Theory of Human Motivation, Psychological Review 50, 370-96.

Maslow, A.H. (1943). Motivation and personality. New York: Harper. 
Narula, N. (2007). A study of academic achievement in mathematics in relations to emotional intelligence, creativity learning styles and mathematical aptitude at high school stage. Ph.D. (Edu.) Thesis, Punjab University Chandigarh.

\section{TABLES}

T1: Showing mean comparison of Tribal and Non- tribal school students on real self dimension of self-actualization

\begin{tabular}{|l|l|l|l|}
\hline Group & N & Mean & SD \\
\hline Tiibal & 150 & 25569 & 21.75 \\
\hline NonTỉbal & 150 & 16847 & 20.70 \\
\hline
\end{tabular}

T2: Showing mean comparison of Tribal and Non-tribal school students on ideal self dimension of self actualization inventory

\begin{tabular}{|l|l|l|l|}
\hline Group & N & Mean & SD \\
\hline Tiibal & 150 & 161.14 & 14.12 \\
\hline NonTiibal & 150 & 19817 & 1816 \\
\hline
\end{tabular}

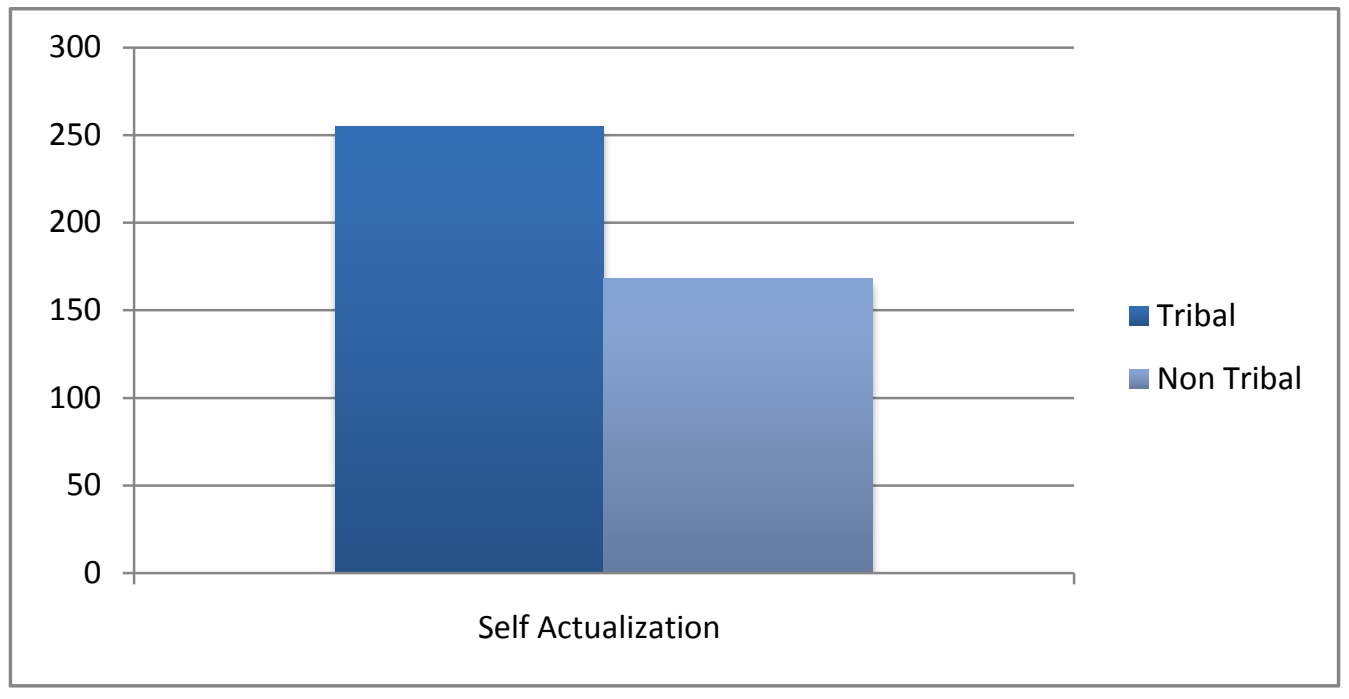

